CentroSur

Social Science Journal

\section{Política de comercio exterior en Ecuador: Un análisis comparativo}

Foreign trade policy in Ecuador: A comparative analysis
Centro Sur

Social Science Journal

Julio - Diciembre Vol 4 No 2

http://centrosureditorial.com/ind

ex.php/revista

eISSN: 2600-5743

revistacentrosur@gmail.com Recepción: 18 marzo 2019

Aprobación 23 abril 2020

Pag 266-284

Atribución/ReconocimientoNoComercial-Compartirlgual 4.0 Licencia Pública Internacional CC BY-NC-SA 4.0 https://creativecommons.org/lice nses/by-nc-sa/4.0/legalcode.es

Manuel Ruvin Quiñónez Cabeza ${ }^{1}$

Luisa Nicole Quiñónez Caicedo²

\section{Resumen}

Este artículo analiza las políticas de comercio exterior ecuatorianas durante el periodo 2014-2018, utilizando el método comparativo, con técnica descriptiva y documental que permitió estudiar los indicadores de comercio exterior y política comercial, tomando los datos del Banco Central del Ecuador y del Sistema Gráfico de Comercio Internacional de la CEPAL. Los resultados evidenciaron una disminución de la balanza comercial en el 2015 de 1,94\% con relación al 2014 , un aumento de $-1,59 \%$ en el 2016 , una reducción en el 2017 de $-0,93 \%$ y de $6,77 \%$ en el 2018. Se concluyó que la política de comercio exterior del Buen Vivir tuvo una acertada gestión de los instrumentos de política comercial; No obstante, los resultados no mostraron lo mismo de la política comercial Toda una Vida, sin embargo, se debe esperar a finalizar el periodo.
Palabras clave: : Comercio Exterior, Instrumentos, Política, Buen Vivir, Toda una Vida, Comercio.

\footnotetext{
1. Doctor en Economía. Universidad Técnica Luis Vargas Torres, Esmeraldas, Ecuador. ORCID. https://orcid.org/0000-0001-7617-6705. Email. ruvin1967@gmail.com. Google académico https://scholar.google.es/citations?hl=es\&user=ZiR4ZnE AAAAJ

2. Maestrante. Universidad Inteernacional de la Rioja, Universidad Tecnológica Empresaria de Guayaquil UTEG. Guayaquil, Ecuador. ORCID. https://orcid.org/0000-0002-7449-9225. Email. nicoleqc1997@gmail.com. Google académico https://scholar.google.es/citations?hl=es\&user=Eg94AoAAAAJ
} 


\section{Abstract}

This article analyzes the Ecuadorian foreign trade policies during the 20142018 period, using the comparative method, with a descriptive and documentary technique that allowed studying the indicators of foreign trade and commercial policy, taking data from the Central Bank of Ecuador and the Graphic System of International Trade of CEPAL. The results evidenced a decrease in the trade balance in 2015 of $1.94 \%$ compared to 2014 , an increase of $-1.59 \%$ in 2016 , a reduction in 2017 of $-0.93 \%$ and $-6,77 \%$ in 2018 .
It was concluded that the Buen Vivir foreign trade policy had the right management of trade policy instruments; However, the results did not show the same of the commercial policy for a lifetime, however, we must wait until the end of the period.

Key words: Foreign Trade, Instruments, Politics, Good Living, A Lifetime, Trade.

\section{Introducción}

La política de comercio exterior es un instrumento de negociación internacional que facilita las transacciones comerciales entre países; permite a las economías proteger su industria interna al desincentivar la importación de productos extranjeros, a la vez que incrementa la demanda del producto nacional. En este sentido: ¿cuáles fueron las políticas de comercio exterior ecuatoriana durante el periodo 2014-2018? Se plantea como objetivo general hacer un análisis comparativo las políticas de comercio exterior ecuatoriana durante el periodo 2014-2018, para lo cual se establecieron los siguientes objetivos específicos:

- Describir las políticas de comercio exterior del Ecuador durante 2014-2018.

- Determinar los Acuerdos Comerciales firmados por Ecuador durante 2014-2018.

- Analizar el comercio exterior del Ecuador en el marco de las políticas de comercio exterior durante 2014-2018.

El contexto de la presente investigación está integrado por un marco teórico donde se exponen los datos recopilados de fuentes secundarias; la metodología se realizó a través de un estudio comparativo que permitió obtener los resultados y las conclusiones.

\section{Materiales y métodos}

Se utilizó el método comparativo que permitió hacer un análisis de las diferencias o las semejanzas (concordancias) (Gómez Díaz de León \& León de la Garza, 2014) de las políticas de comercio exterior del Ecuador del Buen Vivir y Toda una Vida, a través 
del tipo de investigación descriptivo para explicar las políticas y determinar los acuerdos comerciales firmados por Ecuador en el marco de las políticas, y analizar los indicadores de comercio exterior y política comercial apoyándose en la técnica documental para obtener información de fuentes secundarias.

\section{Resultados}

La política comercial permite regular y mantener las relaciones comerciales de una economía con el resto del mundo, a través de instrumentos y normas como la política arancelaria y cuotas de importación e incentivos para las exportaciones (Organización de las Naciones Unidas para la Agricultura y la Alimentación, 2004); estos instrumentos permiten a las economías proteger su industria interna, desincentivan la importación de productos extranjeros, e incrementar la demanda del producto nacional. Por otra parte, junto con otras políticas como cambiaria y monetaria son instrumentos de la política económica (Cuenca Coral, Amaya, \& Castrillón, 2014) que contribuyen a corregir el déficit en la balanza de pagos, debido al tipo de cambio.

Además de instrumentos, la Política de comercio exterior abarca medidas que favorecen la apertura comercial tales como la eliminación de las restricciones a la importación y controles a la exportación (Organización de las Naciones Unidas para la Agricultura y la Alimentación, 2004). En este sentido, la filosofía de gobierno tiene un papel muy importante en el diseño de la política comercial y de gestionar sus instrumentos (Steinberg Wechsler, 2006); un gobierno capitalista define una política comercial de libre mercado y sus relaciones internacionales están enfocadas en negociar con países de economía abierta, firmar más acuerdos comerciales y tener políticas internas que favorezcan estas relaciones.

Por el contrario, un gobierno cuya tendencia no esté a favor del libre mercado o del capitalismo, plantea una política comercial proteccionista, es decir, aplicará medidas proteccionistas para proteger temporalmente la industria y producción nacional (Gibbs, 2007). La política de comercio exterior como política pública debe ser evaluada a través de indicadores que determinan la posición comercial y dinamismo del comercio del país (Durán Lima \& Alvarez, 2008). A continuación, se presentan algunos de los principales indicadores a analizar en el presente estudio como: saldo de la balanza comercial, valor de las exportaciones, índice de cobertura, índice de concentración o de Hirschman-Herfindahl $(\mathrm{IHH})$, e índice de similitud.

Definición 1 (Saldo de la balanza comercial). Es el resultado del saldo total de las exportaciones de un país durante un determinado periodo restados del total de las importaciones en el mismo periodo; un saldo positivo, indica una balanza comercial Superavitaria, mientras que un saldo negativo, se conoce como deficitario. 
Definición 2 (Valor de las exportaciones de bienes). Las exportaciones son el conjunto de bienes producidos domésticamente y vendidos al exterior (Durán Lima \& Alvarez, 2008).

Definición 3 (Índice de cobertura). Mide el valor total de las exportaciones que pueden pagar las importaciones (Velín \& Medina, 2011). La relación se expresa algebraicamente de la siguiente manera:

$$
T C_{t}^{i}=\frac{E_{t}^{i}}{I_{t}^{i}} * 100
$$

Donde: TC=Tasa de Cobertura; E=Exportaciones; I=Importaciones; i=País de origen; $\mathrm{t}=$ Periodo de tiempo. Así, cuando las exportaciones son mayores a las importaciones, el resultado es mayor a 100 e indica un saldo de la balanza superavitario; cuando las importaciones son mayores a las exportaciones, el resultado es menor a 100 e indica un saldo deficitario.

Definición 4 (Índice de Hirschman-Herfindahl). Mide la diversificación/concentración de un país 'reporter' con respecto a todos los países del mundo en el total de sus exportaciones o importaciones (CEPAL, s.f.)

$$
\mathrm{IHH}=\sum_{\mathrm{j}=1}^{\mathrm{n}}\left(\frac{\mathrm{X}_{\mathrm{ij}}}{\mathrm{X}_{\mathrm{iw}}}\right)^{2}
$$

Donde: $\mathrm{X}=$ Exportaciones; $\mathrm{j}=$ Países de destino; $\mathrm{i}=$ País de origen; $\mathrm{w}=\mathrm{El}$ mundo

Valores del índice, de acuerdo a la CEPAL:

Entre 0 y 0.15 : Diversificado

Entre 0.15 y 0.25 : Moderadamente concentrado

Mayor que 0.25: Concentrado

Definición 5 (Índice de similaridad). Calcula la similitud de la canasta de productos de las exportaciones de un país o región a un mercado homogéneo (Durán Lima \& Alvarez, 2008)

$$
\text { IS }=\sum_{\mathrm{k}=1}^{\mathrm{n}} \operatorname{Min}\left[\frac{\mathrm{x}_{\mathrm{i}}^{\mathrm{k}}}{\mathrm{x}_{\mathrm{i}}}, \frac{\mathrm{x}_{\mathrm{j}}^{\mathrm{k}}}{\mathrm{x}_{\mathrm{j}}}\right]
$$

Donde: $\mathrm{X}=$ Exportaciones totales; $\mathrm{k}=$ Producto; $\mathrm{i}=$ País 1 ; j=País $2 ; \mathrm{n}=$ Número de productos. Resultados del índice: $0=$ Totalmente diferente $1=$ Similares 


\section{Política de Comercio Exterior ecuatoriana}

La política de comercio exterior ecuatoriana está definida dentro del Plan Nacional de Desarrollo (PND) de cada gobierno y se fundamenta bajo la constitución del Ecuador en su artículo 280 (Constitución de la República del Ecuador, 2008). Por otro lado, el órgano responsable de la política comercial es el Comité de Comercio Exterior (COMEX), de acuerdo a lo establecido en el Código Orgánico de la Producción, Comercio e Inversión (COPCI) (Ballén Mancero, 2017). Debido al cambio de gobierno en el 2017 concurrieron dos políticas de comercio exterior contempladas en el Plan Nacional (PN) para el "Buen Vivir" 2013-2017 del gobierno del expresidente Rafael Correa Delgado y el PND "Toda una vida" 2017-2021 del gobierno del presidente Lenín Moreno Garcés.

\section{Política de Comercio Exterior en el marco del Plan Nacional para el "Buen Vivir"}

"Buen vivir" o "Sumak Kawsay" (Pérez-Morón \& Cardoso-Ruiz, 2014) en quechua, es el nombre del PN del tercer gobierno de la Revolución Ciudadana (RC) presidido por el ex presidente Rafael Correa Delgado durante el periodo 2013-2017, diseñado como un conjunto de objetivos para alcanzar la transformación de la matriz productiva y profundizar en el aumento de la productividad real, la diversificación de las exportaciones, de los exportadores y de los destinos mundiales para un mejor desempeño de la economía para el buen vivir (Ordóñez Iturralde \& Hinojosa Dazza, 2014). Al igual que todo PN del Ecuador, la política de comercio exterior contemplada en el PN del "Buen Vivir" está alineada a los principios del artículo 416 de la constitución del Ecuador y 304 que establece dinamizar el mercado nacional e impulsar la inserción estratégica del Ecuador en el mundo (Constitución de la República del Ecuador, 2008).

De este modo, la política de comercio exterior de la RC enmarcada bajo el PND 20132017 se rige bajo la Constitución del Ecuador que este PND reconoce dentro de su principio de Soberanía e integración de los pueblos que la libertad, la soberanía y la autodeterminación de los Estados nacionales, crearán un nuevo orden internacional para fomentar la construcción de un mundo multipolar, que un mundo multipolar requiere la participación activa de bloques económicos y políticos regionales (Senplades, 2013).

\section{Política de Comercio Exterior en el marco del Plan Nacional de Desarrollo "Toda una vida"}

El Plan Nacional de Desarrollo "Toda una Vida" es el cuarto plan dentro del marco de planificación de las propuestas y planes a seguir por el partido de la Revolución Ciudadana, iniciado en el 2006 por el ex presidente Rafael Correa Delgado y 
continuado en el 2017 por el presidente Lenín Moreno Garcés. Así como los PND que anteceden, está articulado a la Constitución del Ecuador en sus artículos 416 y 280. Asimismo, los grandes objetivos nacionales están organizados en tres ejes, bajo los cuales en dos se fundamenta la política de comercio exterior: Economía al servicio de la sociedad y Más sociedad, mejor Estado. De este modo, el gobierno de Moreno busca convertir al Ecuador en una economía atractiva para invertir tanto para empresas nacionales como extranjeras, mejorar la producción nacional para aumentar las exportaciones y aprovechar las herramientas de política comercial para reducir las importaciones, con el fin de proteger la economía y afianzar la dolarización (Senplades, 2017).

Cuadro 1 Objetivos de las políticas de comercio exterior durante el periodo 20142018

\begin{tabular}{|c|c|c|c|}
\hline \multicolumn{2}{|c|}{ Política de Comercio Exterior del Buen Vivir } & \multicolumn{2}{|c|}{ Política de Comercio Exterior Toda una Vida } \\
\hline \multicolumn{2}{|c|}{ Base constitucional $280,283,304,416}$. & \multicolumn{2}{|c|}{ Base constitucional 280, 304 y 416} \\
\hline $\begin{array}{l}\text { Objetivos Estratégicos del } \\
\text { Ministerio de Comercio } \\
\text { Exterior }\end{array}$ & $\begin{array}{c}\text { Objetivos en el marco del PND } \\
\text { "El Buen Vivir" }\end{array}$ & $\begin{array}{l}\text { Objetivos en el marco del } \\
\text { PND "Toda una vida" }\end{array}$ & $\begin{array}{c}\text { Ministerio de } \\
\text { Productividad, } \\
\text { Comercio Exterior, } \\
\text { Inversiones y Pesca }\end{array}$ \\
\hline $\begin{array}{l}\text { - Incrementar la inserción } \\
\text { estratégica económica y } \\
\text { comercial en el mundo. } \\
\text { - Aumentar las exportaciones } \\
\text { No Petroleras en valor y en } \\
\text { volumen y los flujos de } \\
\text { inversión extranjera directa } \\
\text { con énfasis en los sectores } \\
\text { priorizados y en el cambio de } \\
\text { la matriz productiva. } \\
\text { - Reducir el déficit de la } \\
\text { Balanza Comercial No } \\
\text { Petrolera haciendo énfasis en } \\
\text { la sustitución selectiva de las } \\
\text { importaciones. }\end{array}$ & $\begin{array}{l}\text { - Profundizar la inserción } \\
\text { estratégica en el mundo y la } \\
\text { integración latinoamericana. } \\
\text { - Construir procesos de ruptura } \\
\text { con realidades existentes, a } \\
\text { través de la consolidación de } \\
\text { mecanismos de integración } \\
\text { entre los países del Sur y } \\
\text { latinoamericanos. } \\
\text { - Diversificar mercados y oferta } \\
\text { exportable. } \\
\text { - Romper las condiciones de } \\
\text { dependencia económica. } \\
\text { - Impulsar la participación en las } \\
\text { exportaciones de productos de } \\
\text { las MIPYMES y del sector de la } \\
\text { economía popular y solidaria. }\end{array}$ & $\begin{array}{l}\text { - Posicionar } \\
\text { estratégicamente al país } \\
\text { en la región y el mundo. } \\
\text { - Diversificación de de } \\
\text { mercados y oferta } \\
\text { exportable con valor } \\
\text { agregado, apoyando a } \\
\text { pequeños y grandes } \\
\text { productores y y } \\
\text { fortaleciendo esquemas } \\
\text { de comercio justo y } \\
\text { equitativo. } \\
\text { - Atraer inversión nacional } \\
\text { y extranjera. } \\
\text { - Impulsar políticas que } \\
\text { consoliden la sustitución } \\
\text { de importaciones. } \\
\text { - Profundizar el proceso de } \\
\text { integración con América } \\
\text { Latina, el Caribe y los } \\
\text { países vecinos, como } \\
\text { espacio de convergencia } \\
\text { política y } \\
\text { complementariedad y } \\
\text { económica, logística, } \\
\text { estratégica. }\end{array}$ & 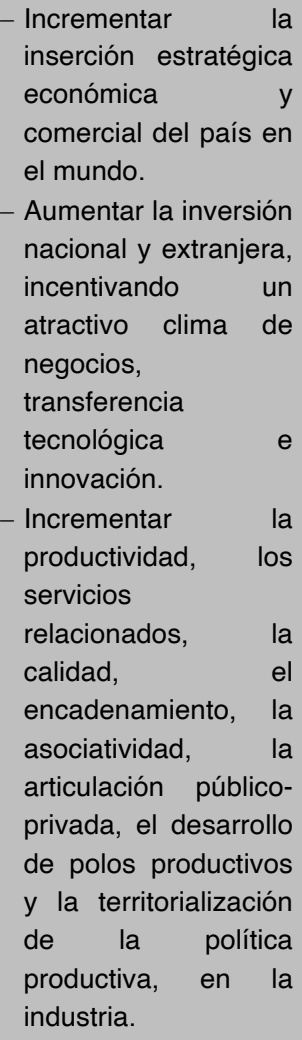 \\
\hline
\end{tabular}




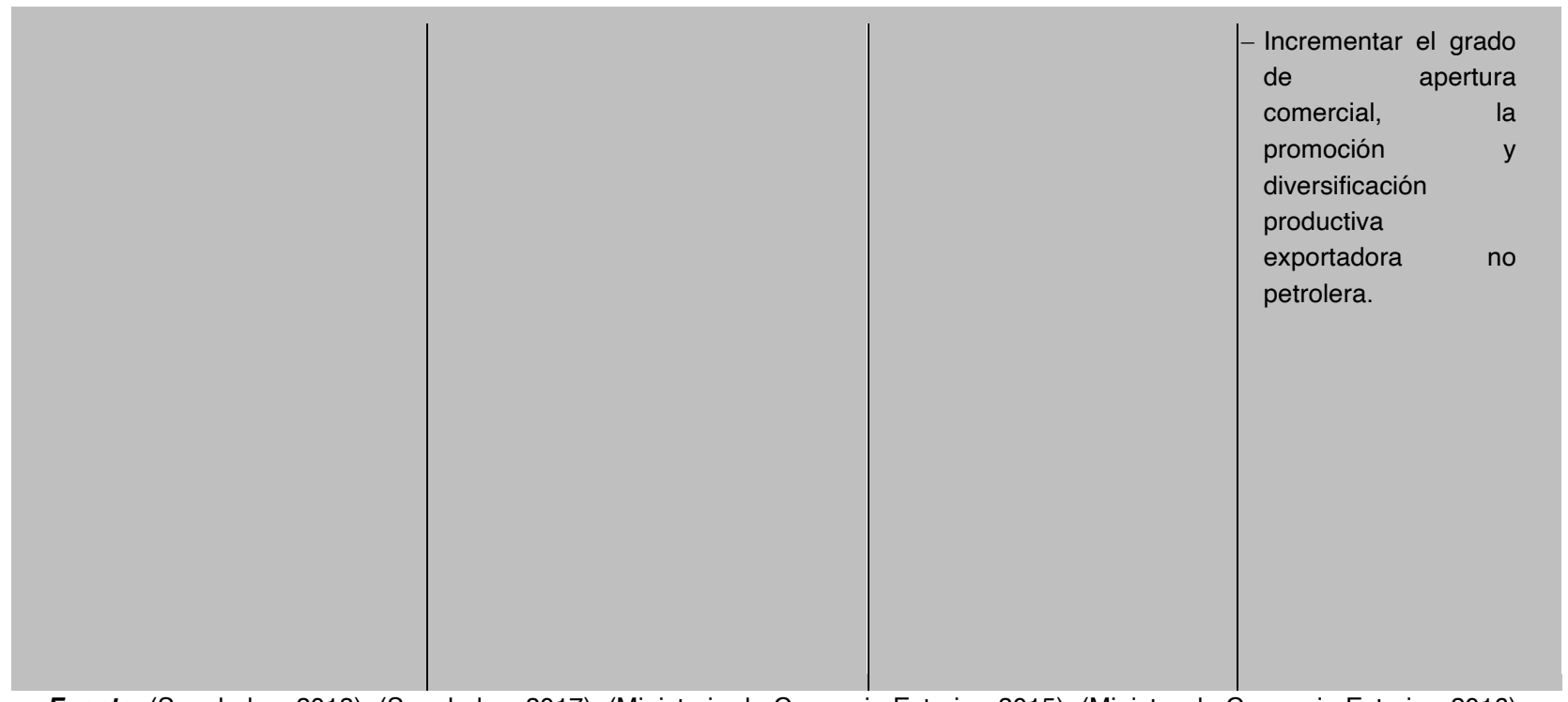

Fuente: (Senplades, 2013), (Senplades, 2017), (Ministerio de Comercio Exterior, 2015), (Ministro de Comercio Exterior, 2016), (Ministerio de Comercio Exterior, 2017), (Ministerio de Comercio Exterior e Inversiones, 2018) y (Ministerio de Producción, Comercio Exterior, Inversiones y Pesca, 2019)

Cuadro 2 Acuerdos comerciales firmados durante el periodo 2014-2018

\begin{tabular}{|c|c|c|}
\hline & $\begin{array}{l}\text { Política de Comercio } \\
\text { Exterior del Buen Vivir }\end{array}$ & $\begin{array}{l}\text { Política de Comercio } \\
\text { Exterior Toda una Vida }\end{array}$ \\
\hline $\begin{array}{l}\text { Inserción } \\
\text { Estratégica y } \\
\text { Comercial }\end{array}$ & $\begin{array}{l}\text {-Acuerdo Comercial } \\
\text { Multipartes con la Unión } \\
\text { Europea, entró en vigencia } \\
\text { en el } 2017 \text {. } \\
\text {-Acuerdo de Alcance Parcial } \\
\text { con Nicaragua, suscrito el } \\
05 \text { de julio de } 2016 \text {. } \\
\text {-Acuerdo de Alcance Parcial } \\
\text { con El Salvador, suscrito el } \\
13 \text { febrero } 2017 \text {. }\end{array}$ & $\begin{array}{l}\text {-Acuerdo de Asociación } \\
\text { Económica con los estados } \\
\text { de la Asociación Europea } \\
\text { de Libre Cambio (AELC). } \\
\text { - Acuerdos de Cooperación } \\
\text { en Materia de Origen con } \\
\text { los Ministerios de } \\
\text { Comercio de: Costa Rica, } \\
\text { Honduras, Guatemala, } \\
\text { Nicaragua y El Salvador. }\end{array}$ \\
\hline
\end{tabular}

Fuente: (Ministerio de Producción, Comercio Exterior, Inversiones y Pesca) 


\section{Indicadores de Comercio Exterior y Política Comercial}

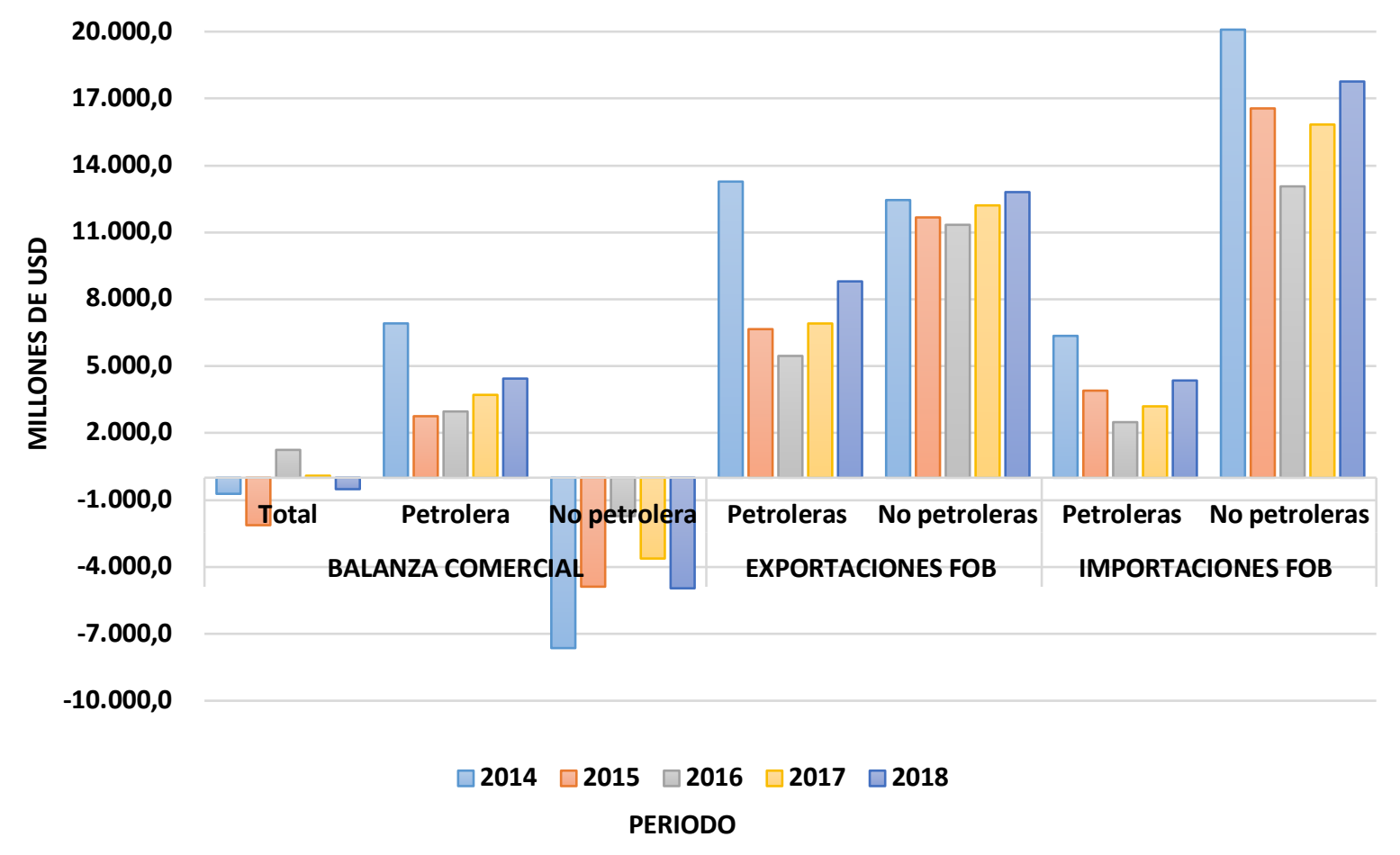

Figura \#1 Balanza Comercial Total Petrolera y No petrolera. Fuente: (Banco Central del Ecuador) 


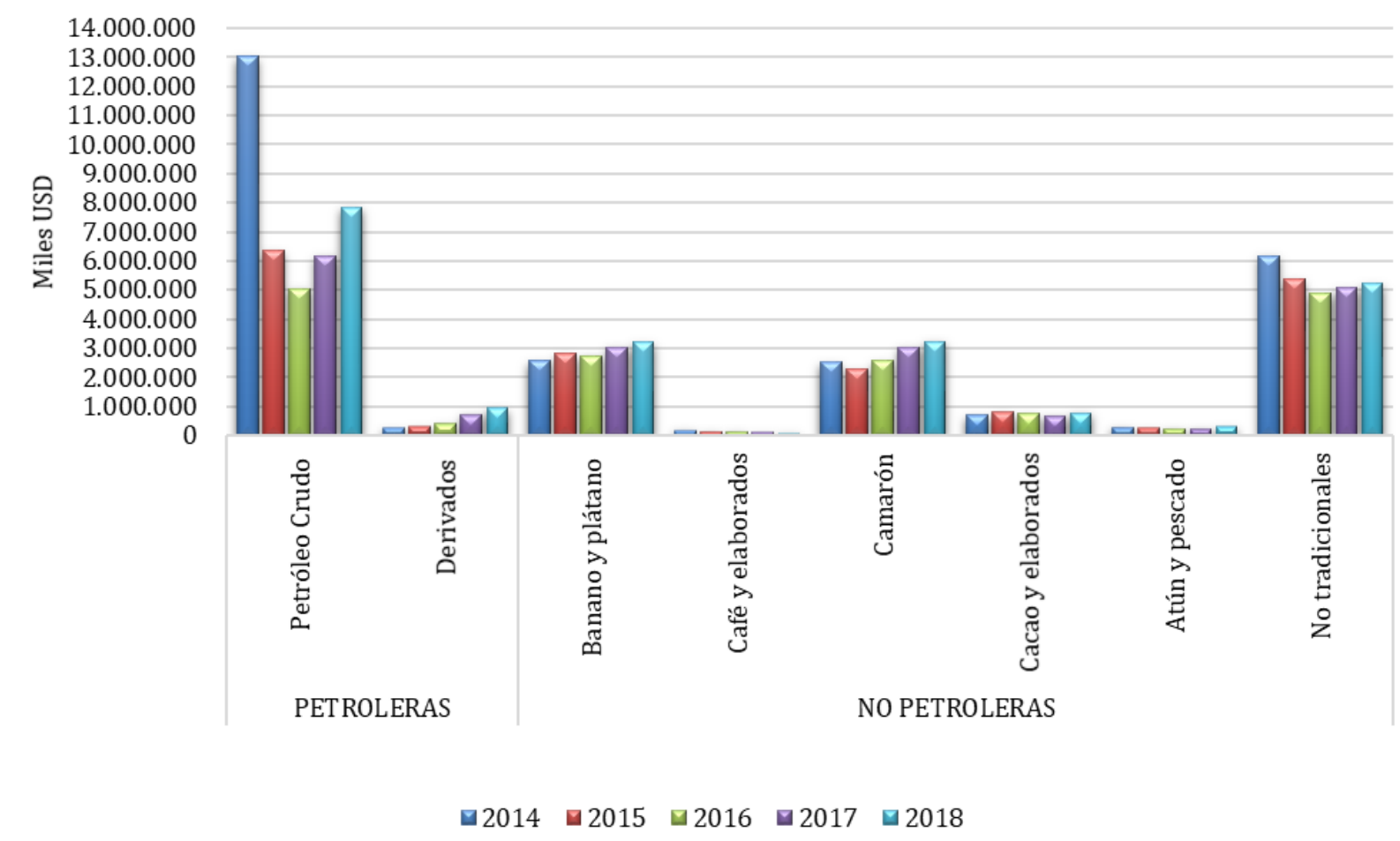

Figura \#2 Exportaciones por grupos de productos. Fuente: (Banco Central del Ecuador).

Tabla 1 .Exportaciones FOB anuales por continente y área económica en MMUSD

\begin{tabular}{|c|c|c|c|c|c|c|}
\hline \multirow{2}{*}{\multicolumn{2}{|c|}{ Total }} & 2014 & 2015 & 2016 & 2017 & 2018 \\
\hline & & 25.724 & 18.330, & 16.797, & 19.122, & 21.606, \\
\hline \multirow{4}{*}{$\begin{array}{c}\text { Améric } \\
\text { a }\end{array}$} & Estados Unidos & $\begin{array}{c}11.239 \\
6\end{array}$ & $7.226,2$ & $5.436,1$ & $6.056,9$ & $6.671,5$ \\
\hline & ALADI (1) & $4.814,0$ & $2.430,3$ & $2.530,3$ & $2.793,2$ & $3.297,7$ \\
\hline & CAN & $2.559,2$ & $1.754,7$ & $1.776,4$ & $2.084,7$ & $2.484,7$ \\
\hline & $\begin{array}{l}\text { Canadá } \\
\text { Mercado Común }\end{array}$ & 119,5 & 117,2 & 77,9 & 86,4 & 87,4 \\
\hline & $\begin{array}{c}\text { Centroamerican } \\
0\end{array}$ & 174,7 & 172,6 & 174,3 & 179,5 & 259,3 \\
\hline \multirow{6}{*}{ Europa } & Resto América & 144,9 & 70,0 & 88,1 & 83,4 & 141,4 \\
\hline & UE & $2.981,3$ & $2.773,0$ & $2.831,7$ & $3.173,4$ & $3.268,9$ \\
\hline & EFTA & 80,6 & 51,5 & 33,2 & 29,2 & 27,2 \\
\hline & Resto Europa & 990,9 & 851,9 & 869,3 & 941,1 & 936,1 \\
\hline & Asia & $2.432,8$ & $2.707,7$ & $2.842,3$ & $3.594,8$ & $4.291,1$ \\
\hline & África & 122,3 & 104,9 & 65,1 & 42,9 & 83,3 \\
\hline
\end{tabular}




\begin{tabular}{c|c|c|c|c|c}
\hline Oceanía & 45,0 & 50,9 & 52,3 & 53,9 & 53,8 \\
Resto del mundo & 19,6 & 19,8 & 20,8 & 3,1 & 3,8 \\
\hline
\end{tabular}

(1) ALADI sin países de la CAN

Fuente: (Banco Central del Ecuador)

Cuadro 3. Interpretación de los datos

\begin{tabular}{|c|c|c|}
\hline & $\begin{array}{c}\text { Política de Comercio Exterior del } \\
\text { Buen Vivir }\end{array}$ & $\begin{array}{l}\text { Políticas de Comercio } \\
\text { Exterior Total una Vida }\end{array}$ \\
\hline $\begin{array}{l}\text { Balanza } \\
\text { Comercial } \\
\text { Total }\end{array}$ & $\begin{array}{l}\text { 2014: - } 723,2 \\
\text { 2015: }-2.129,6 \\
\text { 2016: } 1.247,0 \\
\text { Decrecimiento en el } 2015 \text { de } 1.406,1 \\
\text { (1,94\%) MMUSD con relación al } 2014 \\
\text { y un aumento en } 3.376,7 \text { MMUSD (- } \\
\text { 1,59\%) en el } 2016 \text {, registrando un } \\
\text { saldo total superavitario. }\end{array}$ & $\begin{array}{l}\text { 2017: } 89,2 \\
\text { 2018: -514,5 } \\
\text { Reducción de } 1.157,8 \\
\text { MMUSD (-0,93\%) en el } 2017 \text {, } \\
\text { en comparación al } 2016 \text { y en } \\
\text { el } 2018 \text { de } 603,7 \text { MMUSD (- } \\
\text { 6,77\%), cerrando con un saldo } \\
\text { comercial deficitario. }\end{array}$ \\
\hline $\begin{array}{l}\text { Valor de las } \\
\text { Exportacio } \\
\text { nes No } \\
\text { Petroleras }\end{array}$ & $\begin{array}{l}\text { 2014: } 12.448,6 \\
\text { 2015: } 11.670,3 \\
\text { 2016: } 11.338,5 \\
\text { Disminución constante en el } 2015 \text { de } \\
\text { 778,3 MMUSD en comparación al } \\
\text { 2014 y en el } 2016 \text { de 331,8 MMUSD, } \\
\text { en relación al } 2015 \text {. }\end{array}$ & $\begin{array}{l}\text { 2017: } 12.208,9 \\
\text { 2018: } 12.804,4 \\
\text { Aumento en el } 2017 \text { en } 870,4 \\
\text { MMUSD con relación al } 2016 \text {, } \\
\text { y en 595,6 MMUSD, en el } \\
2018 \text {, manteniéndose un } \\
\text { saldo de 12.804,4 MMUSD, el } \\
\text { mayor durante este periodo. }\end{array}$ \\
\hline $\begin{array}{l}\text { Importacio } \\
\text { nes }\end{array}$ & $\begin{array}{l}\text { 2014: } 26.447,6 \\
\text { 2015: } 20.460,2 \\
\text { 2016: } 15.550,6 \\
\text { Reducción de } 5.987,4 \text { MMUSD en el } \\
2015 \text { con relación al } 2014 \text { y en } \\
\text { 4.909,6 MMUSD en el } 2016 \text {. }\end{array}$ & $\begin{array}{l}\text { 2017: } 19.033,2 \\
\text { 2018: } 22.120,6 \\
\text { Incremento continuo de } \\
3.482,6 \text { MMUSD y } 3.087,4 \\
\text { MMUSD en el } 2017 \text { y } 2018 \\
\text { respectivamente. }\end{array}$ \\
\hline
\end{tabular}




\begin{tabular}{|c|c|c|}
\hline $\begin{array}{l}\text { Valor de las } \\
\text { Exportacio } \\
\text { nes No } \\
\text { Tradicional } \\
\text { es }\end{array}$ & $\begin{array}{l}\text { 2014: } 6.172 .998 \\
\text { 2015: } 5.365 .846 \\
\text { 2016: } 4.881 .229 \\
\text { Reducción en } 807.153 \text { Miles USD al } \\
2015 \text { y de } 484.617 \text { Miles USD al } \\
2016 \text {. }\end{array}$ & $\begin{array}{l}\text { 2017: } 5.085 .580 \\
\text { 2018: } 5.209 .487 \\
\text { Ligero incremento de } 204.351 \\
\text { Miles USD en el } 2017 \text { y } \\
123.907 \text { miles USD en el } \\
2018 \text {. }\end{array}$ \\
\hline $\begin{array}{l}\text { Destino de } \\
\text { las } \\
\text { Exportacio } \\
\text { nes por } \\
\text { continente } \\
\text { y área } \\
\text { económica }\end{array}$ & $\begin{array}{l}\text { Estados Unidos lideró la lista como } \\
\text { principal destino de las exportaciones } \\
\text { ecuatorianas durante los tres años: } \\
2014,2015 \text { y } 2016 \text {. } \\
\text { En el } 2014 \text {, la ALADI y UE ocuparon } \\
\text { el segundo y tercer lugar } \\
\text { respectivamente, seguidos de la CAN } \\
\text { y Asia en el cuarto y quinto lugar. } \\
\text { Al } 2015 \text {, la UE y Asia ocuparon el } \\
\text { segundo y tercer lugar, la ALADI y el } \\
\text { bloque de la CAN el cuarto y quinto } \\
\text { lugar. } \\
\text { Para el } 2016 \text {, Asia ocupa el segundo } \\
\text { lugar seguido de la UE en tercero y la } \\
\text { ALADI y CAN el cuarto y quinto } \\
\text { puesto respectivamente. }\end{array}$ & $\begin{array}{l}\text { En el } 2017 \text { y } 2018 \text { Estados } \\
\text { Unidos continúa como destino } \\
\text { principal. En estos años la lista } \\
\text { de los } 5 \text { principales bloques } \\
\text { como destinos de las } \\
\text { exportaciones se mantiene } \\
\text { invariable con respecto al } \\
2016 \text {, con un cambio en el } \\
2018 \text { donde la ALADI ocupa el } \\
\text { tercer, Asia cuarto y la CAN se } \\
\text { mantiene en quinto lugar. }\end{array}$ \\
\hline
\end{tabular}

(1) ALADI sin países de la CAN

Fuente: (Banco Central del Ecuador) 


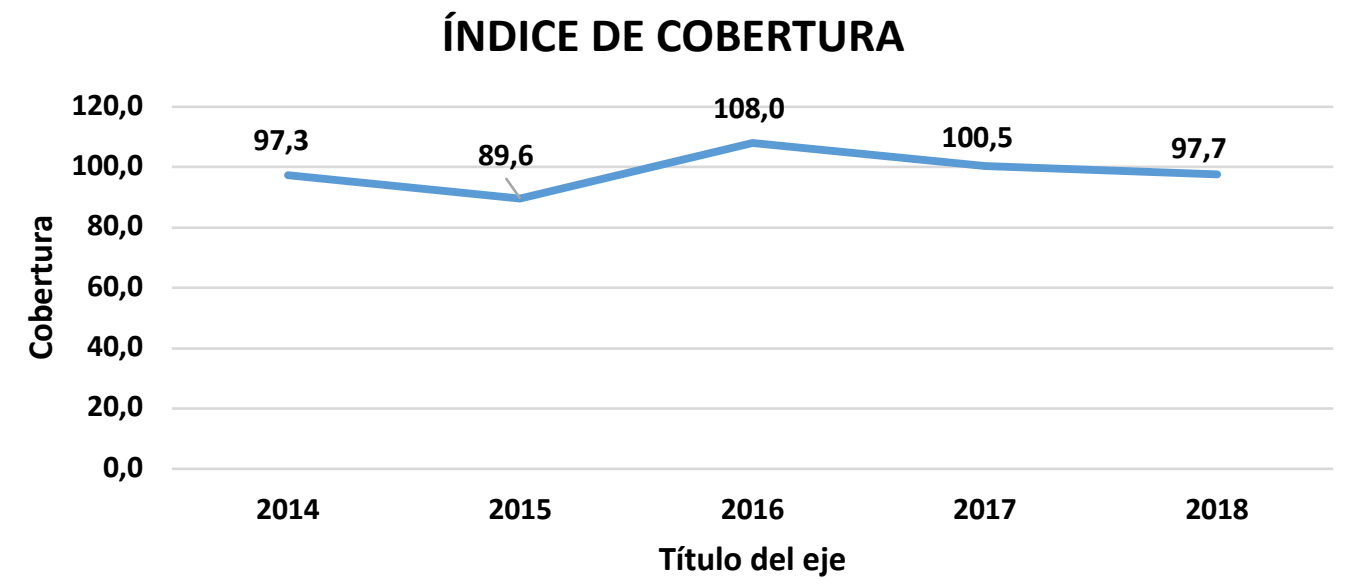

Figura \#3 Índice de cobertura Fuente: (Banco Central del Ecuador)

ÍNDICE DE HERFINDAHL E HIRSCHMAN [PRODUCTOS]

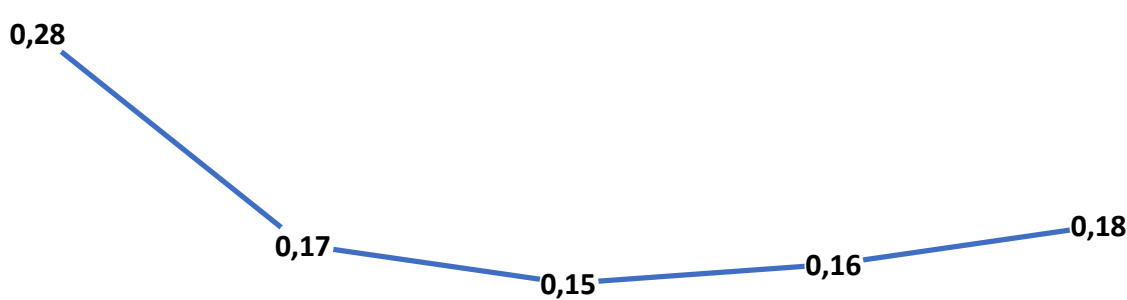

2014

2015

2016

2017

2018

Periodo

Figura \#4. Fuente: CEPAL 


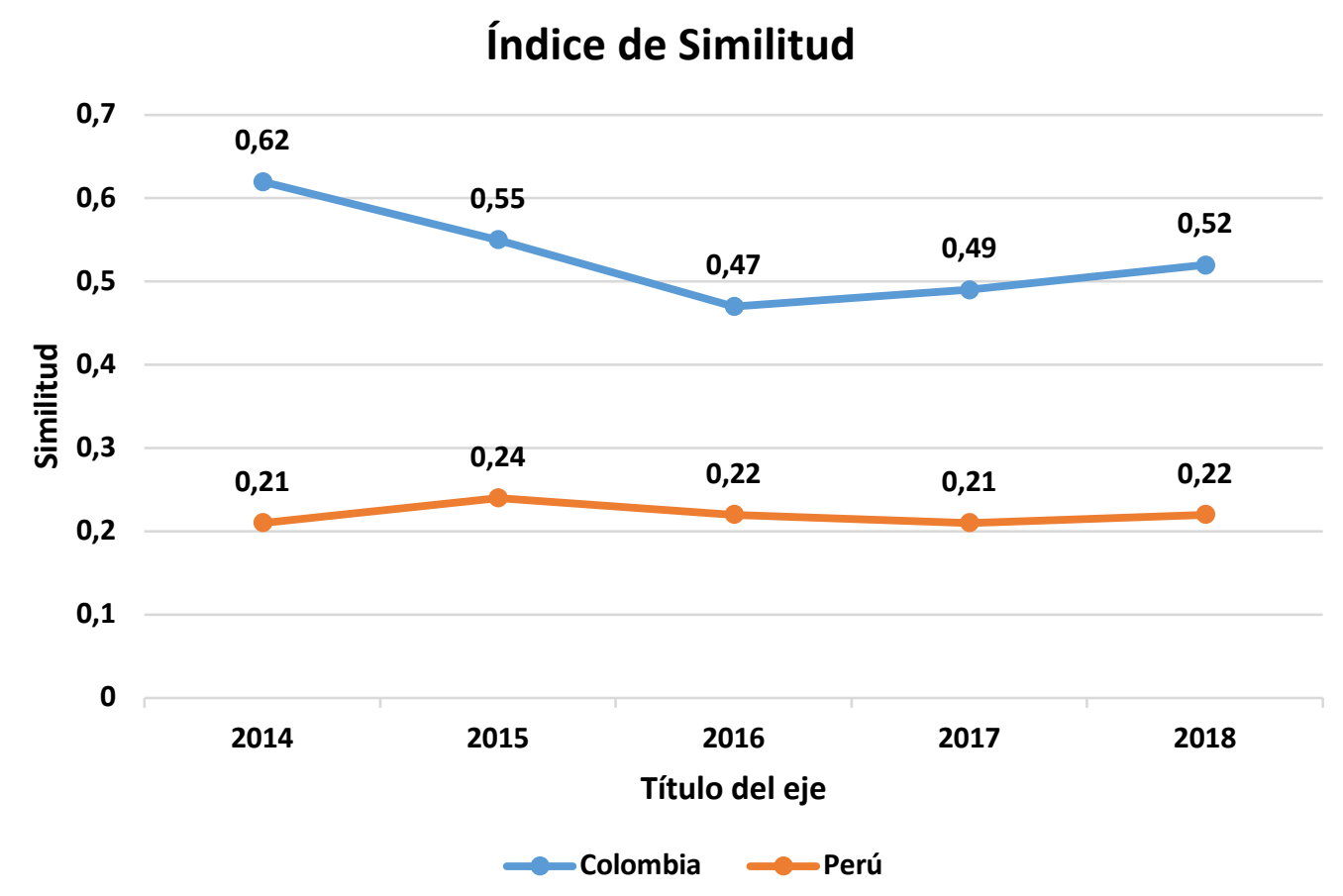

Figura \#5. Fuente: CEPAL.

\section{Discusión}

Las políticas de comercio exterior contempladas en el PND del Buen Vivir y Toda una Vida guardan una amplia similitud respecto a sus objetivos (cuadro \#1), buscan reducir el déficit en la balanza comercial por medio de la sustitución selectiva de importaciones, diversificar mercados y aumentar la oferta exportable para romper con la dependencia de las exportaciones de productos petroleros y tradicionales. De igual forma, apoyar a las micro y pequeñas empresas para incentivar la producción, así como el comercio justo en la economía. También, insertar e integrar al Ecuador en el mundo con lo cual se proyecta ser un destino para la inversión nacional y extranjera, aunque, durante la política del Buen Vivir se buscó romper relaciones con organismos y economías que no compartan los mismos intereses políticos, no obstante, al igual que la política Toda una Vida, persiguió la consolidación y fortalecimiento de la integración con países del Sur y América Latina y el Caribe, principalmente con los bloques económicos en los que forman parte como: la Unasur (Unión de Naciones Suramericanas), la Celac (Comunidad de Estados Latinoamericanos y Caribeños y el ALBA (Alianza Bolivariana para los Pueblos de Nuestra América); en tanto que, la política comercial Toda una Vida procura profundizar los procesos económicos y 
comerciales con países de la CAN (Comunidad Andina de Naciones), Mercosur (Mercado Común del Sur), Alianza del Pacífico y las principales economías.

Con relación a los indicadores de comercio exterior y política comercial, los datos arrojaron que: el saldo de la balanza comercial (gráfico \#1) decreció durante la política del Buen Vivir en 1,94 \% debido a una contracción desde el 2014 de varios sectores y actividades económicas, en especial petroleras, que repercutió en un déficit en la balanza de pagos, por tanto, se adoptaron medidas de salvaguardia por 15 meses, por tipo de cambio, y un recorte en el gasto público (OMC, 2019). En el 2016 aumentó en $-1.59 \%$ alcanzando un saldo positivo en el semestre I; por tanto, en octubre disminuyeron los niveles de sobretasa a 15\% y 35\% (Ministerio de Comercio Exterior, 2017). Mientras que, en el 2017 se dio una reducción de 1.157,8 MMUSD (-0.93\%) por incremento de las importaciones No Petroleras por eliminación de salvaguardias en junio del mismo año, e incurrió en un decrecimiento de $-6.77 \%$ en el 2018 , cerrando con déficit de -514,5 MMUSD.

En cuanto a las exportaciones por grupo de productos (gráfico \#2), el saldo total no petrolero disminuyó constantemente durante la política del Buen Vivir, pero tuvo una recuperación en el periodo de la política Toda una Vida; por otro lado, las exportaciones de productos tradicionales no crecieron significativamente en la política del Buen Vivir, existiendo una fluctuación durante los tres años de análisis; pero incrementó, para el periodo de la política de comercio Toda una Vida; asimismo, las exportaciones No Tradicionales decrecieron en el marco de la política del Buen Vivir, sin registrarse una mejoría, por el contrario, registraron un ligero incremento del $4.19 \%$ a partir del 2017 y del $2.44 \%$ al 2018 en el periodo de la política Toda una Vida.

En relación a los destinos de las exportaciones ecuatorianas por continente, área económica y países (tabla \#1), tomando los cinco primeros lugares, Estados Unidos permanece como principal destino de las exportaciones totales durante todo el periodo, aunque con un decrecimiento constante pasando de $43.69 \%$ en el 2014 a $30.88 \%$ en el 2018. Sin embargo, la tabla muestra que en el periodo de las políticas comerciales no hubo diversificación en los destinos de las exportaciones por área económica, únicamente se presentó una variación en el total exportado a cada área.

Con respecto a los indicadores que miden el dinamismo comercial, los datos tomados del Sistema Gráfico de Comercio Internacional (SIGCI) de la CEPAL mostraron los siguientes resultados: el índice de cobertura (gráfico \#3) se ubicó en menos de 100, 97.3 y 89.6 en el 2014 y 2015 respectivamente, es decir, el valor total de las divisas que ingresaron al país por las exportaciones no compensaron el total que salieron por las importaciones, o como se muestra en el gráfico \#1, el saldo de la balanza comercial fue deficitario; en cambio, en el 2016 arrojó un coeficiente mayor, 108, que muestra 
una mejoría en la economía y un saldo comercial superavitario, cabe mencionar que previo a este año se aplicó la medida de salvaguardia y recorte del gasto público. Por otra parte, el índice cae en el 2017 en 7.6 puntos ubicándose en 100.5, luego de eliminarse la medida de salvaguardia, y en 2.8 puntos en el 2018 con relación al año anterior; dicho de otra manera, en el marco de la política Toda una Vida el valor total que ingresó al país por exportaciones no compensó la salida de divisas por las importaciones.

Igualmente, los datos obtenidos del índice de concentración basado en el índice de Herfindahl e Hirschman (gráfico \#4) muestran que, las exportaciones ecuatorianas eran muy concentradas en el $2014,0.28$, dado que, como se aprecia en el gráfico \#2 del total de las exportaciones en el 2014 , el $52 \%$ fueron de petróleo y sus derivados. En el 2015, el índice decreció 0.11 puntos, posándose en 0.17 , esto es, las exportaciones fueron "moderadamente concentradas", pero en el 2016, el índice decrece a 0.15 , lo que significa que las exportaciones ecuatorianas pasaron de ser concentradas a diversificadas en el marco de la política del Buen Vivir. Por el contrario, el índice aumenta ligeramente en el marco de la política Toda una Vida a 0.16 y 0.18 en el 2017 y 2018 respectivamente, ubicando nuevamente a las exportaciones ecuatorianas como moderadamente concentradas.

Por último, el índice de similaridad (gráfico \#5) con Colombia y Perú mostró que la estructura exportadora de Ecuador guardó gran similitud con Colombia en comparación a Perú. Sin embargo, frente Colombia disminuyó en el marco de la política comercial del Buen Vivir pasando de 0.62 en el 2014 a 0.47 en el 2016, pero aumentó en el marco de la política Toda una Vida de 0.49 en el 2017 a 0.52 en el 2018. En cambio, con Perú fluctuó en el periodo de la política del Buen Vivir de 0.21 en el 2014, a 0.24 en el 2015 y 0.22 al 2016; y aumentó ligeramente de 0.21 en el 2017 a 0.22 en el 2018 durante la política comercial Toda una Vida, En general, en el marco de la política Toda una Vida existió mayor competencia con Colombia comparado al periodo de la política del Buen Vivir, mientras que frente a Perú había un grado de competencia bajo.

\section{Conclusiones}

Las políticas de comercio exterior durante el periodo 2014-2018 estaban contempladas en el marco del Plan Nacional del Buen Vivir 2013-2017 y Toda una Vida 2017-2021. Durante el periodo analizado, se firmaron cuatro acuerdos comerciales: tres en el marco de la política de comercio exterior del Buen Vivir y uno en el marco de la política de comercio exterior Toda una Vida y otros acuerdos de origen. 
El comercio exterior del Ecuador en el marco de las políticas del Plan Nacional del Buen Vivir 2013-2017 y Toda una Vida 2017-2021 fluctúo. El saldo total de la balanza comercial osciló de un déficit a un aumento superavitario durante la política del Buen Vivir, en tanto que, decreció en el periodo de la política Toda una Vida, finalizando deficitario. Con relación a las exportaciones no petroleras, estas decayeron durante la política del Buen Vivir y aumentaron en el curso de la política comercial Toda una Vida. Igualmente ocurrió con el saldo total de las importaciones, disminuyó continuamente durante la política del Buen Vivir e incrementó en el periodo de la política Toda una Vida.

La política de comercio exterior del Buen Vivir tuvo una acertada gestión de los instrumentos de política comercial; No obstante, los resultados no mostraron lo mismo de la política comercial Toda una Vida, sin embargo, se debe esperar a finalizar el periodo.

\section{Referencia}

Asamblea Constituyente. (2008). Constitución de la República del Ecuador. Montecristi: Editora Nacional. Recuperado el 25 de Agosto de 2019, de http://bivicce.corteconstitucional.gob.ec/local/File/Constitucion_Enmiendas_Int erpretaciones/Constitucion_2008.pdf

Ballén Mancero, J. F. (19 de Abril de 2017). El Universo . Rectificación: Sobre la política comercial en el Ecuador. Quito. Recuperado el 25 de Agosto de 2019, de https://www.eluniverso.com/opinion/2017/04/19/nota/6143422/rectificacionsobre-politica-comercial-ecuador

Banco Central del Ecuador. (s.f.). Información Estadística Mensual . Recuperado el 20 de Agosto de 2019, de Banco Central del Ecuador: https://contenido.bce.fin.ec/home1/estadisticas/bolmensual//EMensual.jsp

CEPAL. (s.f.). Sistema Gráfico de Comercio Internacional. Recuperado el 23 de Agosto de 2019, de https://sgo-win12-wee1.cepal.org/dcii/sigci_documentation/sigci_documentation.html?idioma=e

Cuenca Coral, M. E., Amaya, F., \& Castrillón, B. A. (2014). Revista CIFE. 16, 71-122. Recuperado el 20 de Agosto de 2019, de https://revistas.usantotomas.edu.co/index.php/cife/article/view/3129/3110

Durán Lima, J. E., \& Alvarez, M. (2008). Comisión Económica para América Latina y el Caribe (CEPAL). Recuperado el 23 de Agosto de 2019, de https://repositorio.cepal.org/bitstream/handle/11362/3690/S2008794_es.pdf 
Gibbs, M. (2007). Departamento de Asuntos Económicos y Sociales de Naciones Unidas. Recuperado el 19 de Agosto de 2019, de https://esa.un.org/techcoop/documents/Trade_Spanish.pdf

Gómez Díaz de León, C., \& León de la Garza, E. (2014). Repositorio Académico Digital de la Universidad Autónoma de Nuevo México . Método comparativo. Monterrey, México. Recuperado el 10 de Julio de 2019, de http://eprints.uanl.mx/9943/1/carlos_gomez_diaz_cap11_metodocomparativo_ pdf.pdf

Ministerio de Comercio Exterior. (2015). Ministerio de Comercio Exterior. Obtenido de https://www.comercioexterior.gob.ec/wpcontent/uploads/downloads/2015/04/INFORME-RENDICION-DE-CUENTAS2014.pdf

Ministerio de Comercio Exterior. (2017). Ministerio de Comercio Exterior. Obtenido de https://www.comercioexterior.gob.ec/wpcontent/uploads/downloads/2017/05/Informe-de-Gestion-2016_-1.pdf

Ministerio de Comercio Exterior e Inversiones. (2018). Ministerio de Comercio Exterior e Inversiones. Obtenido de https://www.comercioexterior.gob.ec/wpcontent/uploads/2018/02/MCEI_RC_20173.pdf

Ministerio de Producción, Comercio Exterior, Inversiones y Pesca. (2019). Ministerio de Producción, Comercio Exterior, Inversiones y Pesca. Obtenido de https://www.comercioexterior.gob.ec/wpcontent/uploads/2019/03/Informe_Gestion_MPCEIP_.pdf

Ministerio de Producción, Comercio Exterior, Inversiones y Pesca. (s.f.). Acuerdos Comerciales. Recuperado el 26 de Agosto de 2019, de Ministerio de Producción, Comercio Exterior, Inversiones y Pesca: http://www.produccion.gob.ec/acuerdos-comerciales/

Ministro de Comercio Exterior. (2016). Ministro de Comercio Exterior. Obtenido de https://www.comercioexterior.gob.ec/wpcontent/uploads/downloads/2016/04/Informe-de-Gestion-Institucional-MCE2015.pdf

OMC. (2019). Exámenes de las Políticas Comerciales. Recuperado el 20 de Agosto de 2019, de Organización Mundial del Comercio: https://docs.wto.org/dol2fe/Pages/FE_Search/DDFDocuments/250749/s/WT/T PR/S383.pdf 
Ordóñez Iturralde, D., \& Hinojosa Dazza, S. (30 de diciembre de 2014). Revista Retos. La Política Exterior del Ecuador en el Marco del Plan Nacional del Buen Vivir, 4, 143-155. doi:10.17163.ret.n8.2014.07

Organización de las Naciones Unidas para la Agricultura y la Alimentación. (2004). Organización de las Naciones Unidas para la Agricultura y la Alimentación. Obtenido de http://www.fao.org/3/y5673s/y5673s0n.htm

Pérez-Morón, L. Y., \& Cardoso-Ruiz, R. P. (2014). Redalyc. Construcción del Buen Vivir o Sumak Kawsay en Ecuador: una alternativa al paradigma de desarrollo, 26, 49-66. Toluca, México. Recuperado el 25 de Agosto de 2019, de http://www.redalyc.org/articulo.oa?id=28131424004

Senplades. (2013). Plan Nacional para el Buen Vivir 2013-2017. Quito: Senplades. Obtenido de https://www.unicef.org/ecuador/Plan_Nacional_Buen_Vivir_20132017.pdf

Senplades. (2017). Secretaría Nacional de Planificación y Desarrollo. Plan Nacional de Desarrollo Toda una Vida 2017-2021 . Quito, Ecuador: Senplades. Obtenido de https://www.gobiernoelectronico.gob.ec/wpcontent/uploads/downloads/2017/09/Plan-Nacional-para-el-Buen-Vivir-20172021.pdf

Steinberg Wechsler, F. (2006). La economía política del proteccionismo. 65-96. Recuperado el 21 de Agosto de 2019, de https://repositorio.uam.es/bitstream/handle/10486/4527/30306_80_02.pdf?seq uence $=1$

Velín, M., \& Medina, P. (2011). Analítika: revista de análisis estadístico. Recuperado el 23 de Agosto de 2019, de https://www.ecuadorencifras.gob.ec/Analitika/Descargas/Calculo_y_analisis_d e_indicadores_sectoriales_de_comerio_exterior.pdf 